\title{
DESCAMINHOS ARQUEOLÓGICOS DA DESCONTINUIDADE E DA RECORRÊNCIA EM FOUCAULT
}

\author{
Carlos Eduardo Ribeiro ${ }^{1}$ \\ Universidade Federal do ABC (UFABC) \\ (D) http://orcid.org/0000-0002-0308-0558
}

\begin{abstract}
RESUMO:
$\mathrm{O}$ artigo realiza uma avaliação sobre os afastamentos reais do pensamento arqueológico de Foucault em relação à epistemologia histórica francesa. O objetivo é mostrar que as ideias de descontinuidade e recorrência da epistemologia de Canguilhem provocou efeitos decisivos sobre a arqueologia de Foucault. Mesmo se o arqueólogo do saber evoca uma nova maneira de praticar a história das ciências, a marca epistemológica de Canguilhem parece sempre estar presente.
\end{abstract}

PALAVRAS - CHAVE: Epistemologia; Descontinuidade; Recorrência; Verdade.

\section{ARCHAEOLOGICAL DETOURS OF DISCONTINUITY AND RECURRENCE ON FOUCAULT}

\begin{abstract}
:
The article evaluates the actual distance from Foucault's archaeological thought in relation to French historical epistemology. The objective is to show that the ideas of discontinuity and recurrence of Canguilhem epistemology have had decisive effects on the archeology of Foucault. Even if the archeologist of knowledge evokes a new way of practicing the history of science, the epistemological mark of Canguilhem always seems to be present.
\end{abstract}

KEYWORDS: Epistemology; Discontinuity; Recurrence; Truth.

\footnotetext{
${ }^{1}$ Professor de Filosofia Contemporânea do curso de Filosofia da Universidade Federal do ABC (UFABC), Santo André/SP - Brasil. Email: c.ribeiro@ ufabc.edu.br

Descaminhos arqueológicos da descontinuidade e da recorrência em Foucault - Carlos Eduardo Ribeiro 


\section{Introdução: efeitos de proximidade da paisagem epistemológica}

A justificativa dos padrões de racionalidade que presidem a verdade científica talvez tenha sido a problemática mais geral do projeto filosófico de Foucault - projeto este que, desde seu surgimento, buscou realizar uma história das ciências segundo as condições de existência dos discursos. Essa orientação essencial o filósofo herdou da epistemologia histórica: G. Canguilhem, A. Koyré, J. Cavaillés e G. Bachelard são alguns autores com os quais Foucault compartilha o interesse comum pela história epistemológica das ciências. Mas a compreensão de tal prática, todavia, não é uniforme. De Bachelard a Canguilhem há, decerto, modulações profundas nas investigações e qualquer tentativa de dar uma definição geral seria mais uma caricatura que propriamente revelar o significado da história das ciências no pensamento francês contemporâneo. Não cabe aqui, portanto, separarmos os epistemólogos, distinguindo-os cada qual nos seus particularismos e nos pormenores de seus objetos, temas e métodos; não pretendemos "conferir" tal tradição, no sentido da confirmação de um semblante mais ou menos hegemônico ${ }^{2}$.

Quando questionado sobre seu silêncio em relação a Bachelard quanto à contribuição deste para sua formação intelectual - Foucault declara que, de fato, adotou ao menos dois elementos vindos desse autor: a descontinuidade na história das ciências e "a idéia de um trabalho da razão sobre ela mesma, no momento em que ela constitui os objetos de análise" (FOUCAULT, 2001b, p. 875). De fato, não seria difícil trazer à tona uma prática descontinuísta da história das ciências posta em execução por

\footnotetext{
${ }^{2}$ Descamps mostra bem a pluralidade de modelos que comportou a rubrica epistemologia histórica. Bachelard praticava uma história das ciências progressiva que prega "um pensamento abstrato capaz de arrumar a desordem confusa da percepção [...]. Soberano, o mundo científico efetuava uma gigantesca averiguação, sempre reordenada. Bachelard desejava tirar uma lição filosófica desses triunfos” (DESCAMPS, 1991, p. 13). É possível pensar, neste sentido, no conceito de obstáculo epistemológico que, criticando o imediatismo da experiência, conclamava o epistemólogo a superar este limite a fim de "captar os conceitos científicos em sínteses psicológicas efetivas, isto é, em sínteses psicológicas progressivas, estabelecendo, a respeito de cada noção, uma escala de conceitos, mostrando como um conceito deu origem a outro, como está relacionado a outro. Terá, então, alguma probabilidade de avaliar a eficácia epistemológica. O pensamento científico vai logo aparecer como dificuldade vencida, como obstáculo superado" (BACHELARD, 1996, p. 22-23). Por sua vez, Koyré, por exemplo, se afigura a Descamps como um pensador que "milita pelas dificuldades", isto é, "recusa-se à tentação de tornar mais acessíveis as sutis descobertas dos antigos cedendo às facilidades das traduções numa linguagem moderna" (DESCAMPS, 1991, p. 87). Pode-se lembrar o que dizia Koyré sobre a indissociabilidade entre de uma história das ciências das outras aventuras do espírito humano: "Desde o início de minhas pesquisas fui inspirado pela convicção da unidade do pensamento humano, particularmente nas suas formas as mais elevadas [...] A evolução do pensamento científico [...] não formava, muito menos, uma série independente, mas, ao contrário, estava ligada estritamente àquelas idéias trans-científicas, filosóficas, metafísicas, religiosas (KOYRÉ, 1966, p. 1-2).
} 
Foucault. ${ }^{3}$ Sem muito esforço, outrossim, seria possível exemplificar que tal descontinuidade é um exercício sobre o domínio de racionalidades que, por sua parte, só podem ser aquilatadas no próprio trabalho da razão dita científica.

Lembremos, por outro lado, que trabalhos como Les déviations religeuses et le savoir médical (1968), La situation de Cuvier dans l'histoire de la biologie (1970) e outros são textos embrionários da arqueologia de Foucault e não se preocupam em expor, com um rigor que se pode dizer metodológico, a distinção entre epistemologia e arqueologia. Nesses trabalhos, as transformações epistemológicas nas ciências assumem a perspectiva da descontinuidade e da ruptura, como a própria possibilidade de interpretar os conceitos normativos das ciências da vida. A terminologia aí utilizada, se por vezes recorre à ideia de "arqueologia", ainda não demarca, com distinção definitiva, o que seria um domínio exclusivamente arqueológico. $^{4}$

$\mathrm{Na}$ verdade, a palavra arqueologia (archéologie) vem aparecendo desde Doença mental e personalidade ${ }^{5}$, usada com sentido mais técnico (para definir as trocas sem linguagem entre loucura e desrazão), no Prefácio à História da loucura. ${ }^{6}$ Doravante, apareceria largamente, inclusive nos subtítulos de $O$ nascimento da clínica e As palavras e as coisas; sem falar ainda das muitas ocorrências nas várias entrevistas concedidas entre os anos 1960-1970. Não é nosso intento observar tais ocorrências do termo, nem seu percurso ao longo dos escritos, de modo a apreendê-lo como um conceito autônomo. Devemos constatar, de todo modo, que uma ambiguidade passa a se colocar: se Foucault, desde 1968, quer se distanciar de uma história exclusivamente conceitual e parte dela para estruturar o que chamará de função enunciativa, pode-se afirmar que é no contorno da epistemologia histórica que a arqueologia de Foucault ganha densidade, até dela se afastar, mas nunca por completo.

\footnotetext{
${ }^{3}$ Michel Foucault licenciou-se em psicologia e diplomou-se em psicologia patológica. Sobre o domínio da pesquisa psicológica, por exemplo, é que inicialmente ele empreende a descontinuidade: cf. FOUCAULT, 2001b, p. 165.

${ }^{4}$ Neste trabalho não será convocada, como habitualmente se faz o estudo da arqueologia de Foucault, uma discussão sobre sua formulação como método histórico no campo da racionalidade científica, especialmente no que diz respeito às referências normalmente utilizadas nesse processo: os artigos de 1968 Respostas a uma questão e Sobre arqueologia das ciências - resposta ao Círculo de Epistemologia são discussões preparatórias para $A$ arqueologia do saber e, embora concentrem esforços para, entre outros interesses, marcar as peculiaridade da arqueologia como método histórico novo, esta analise está suficientemente feita. Por exemplo: GROS (2012); RIBAS (2015; 2016).

${ }^{5}$ Diz Foucault: "Em resumo, todo estágio libidinal é uma estrutura patológica virtual. A neurose é uma arqueologia espontânea da libido" (FOUCAULT, 975, p. 20). O texto de 1962 manteve a expressão do texto de 1954.

"Não quis fazer a história desta linguagem, mas a arqueologia deste silêncio" (FOUCAULT, 2001a, p. 188).
} 
O que se pode dizer para situar a arqueologia é que, para acompanharmos a tese de Roberto Machado MACHADO,1981), a arqueologia é o resultado de certo afastamento da epistemologia histórica que compreende a singularização de seu próprio percurso. Machado apresenta, como sabemos, uma leitura feita a partir da tradição epistemológica, além de fazer uma avaliação fundamental da arqueologia enquanto caminho no qual sua trajetória desenha-se. Esse autor defende que a arqueologia foucaultiana, embora ligada à história epistemológica tal como praticada por Canguilhem e Bachelard - denominada, enfaticamente, de a contemporaneidade da arqueologia - inventa, a partir de tal referência, um novo tipo de história. A assim chamada história arqueológica singularizar-se-ia em face da história epistemológica ao localizar um novo campo de racionalidade. Diz Machado: "o importante é que pelo próprio fato de gravitar em torno da questão do homem considerado como uma região ao lado das regiões da natureza e da vida - a démarche arqueológica não se norteia mais pelos mesmos princípios que orientam a história epistemológica" (MACHADO, 1981, p. 11).

$\mathrm{O}$ argumento central de Machado, na apresentação dos novos princípios da arqueologia, é o de que ela se singulariza porque se converte em história dos discursos. A epistemologia não teria alçado esse voo. Afinal, dedica-se ela a ordenar a ciência - referência que Machado faz a Bachelard, ao evocar a própria ambição de cientificidade pretendida pelo epistemólogo. É justamente dessa ambição que, em certo sentido, Foucault se afastaria, pois desejava que a arqueologia abandonasse o progresso da razão presente na epistemologia, que ela fosse independente da ciência e, enfim, que permitisse "uma crítica da própria ideia de racionalidade". Tratase de pensar este deslocamento da ciência para o saber conforme o qual a arqueologia apresenta um novo tipo de problema que a epistemologia não poderia estudar:

[...] parece-nos mesmo que a riqueza do método arqueológico é ser um instrumento capaz de refletir sobre as ciências do homem enquanto saberes - investigando suas condições de existência através da análise do que dizem, como dizem e por que dizem - neutralizando a questão de sua cientificidade e escapando assim ao desafio impossível da recorrência, sem no entanto, abandonar a exigência de realizar uma análise conceitual capaz de estabelecer descontinuidades, não certamente epistemológicas, mas arqueológicas, isto é, ao nível do saberes (MACHADO, 1981, p. 11).

O deslocamento da ciência para o saber corresponderia, pois, à própria trajetória da arqueologia enquanto estabelecimento de uma nova démarche na epistemologia histórica das ciências. Essa marca é a própria categoria de saber, como a análise de práticas discursivas que, sempre passíveis de serem submetidas às regras de formação do enunciado, 
despontam como discursos positivos além da cientificidade de que se julgam criadores. Contudo, cremos que certos efeitos de proximidade com a epistemologia de Canguilhem merecem ser melhor aquilatados.

Foucault vê no pensamento de Canguilhem uma herança direta até seu pensar. O filósofo ressalta a importância da temática das ciências da vida e do sujeito vivente como objeto central da prática canguilheminiana da história das ciências: "Ele (Canguilhem) aprofundou, sobretudo, os problemas das ciências da vida, procurando mostrar como era, de fato, o homem como ser vivente que se colocava em questão nesta experiência" (FOUCAULT, 2001b, p. 875). Vejamos que espécie de começo a epistemologia de Canguilhem ofertou à arqueologia de Foucault e como a questão da recorrência foi modificada, mas não inutilizada, no interior da arqueologia.

\section{O incipit arqueológico: a descontinuidade pelas mãos de Canguilhem}

Em relação à epistemologia, a arqueologia vê-se atuando num limiar de epistemologização ${ }^{7}$, isto é, no limite estabelecido entre uma positividade estabelecida e as figuras epistemológicas que a formaram como tal. Se não se relaciona a uma verdade, ou a uma falsidade, o que implica então a análise arqueológica? Uma posição tardia de Foucault vem esclarecer a questão e que nos interessa avaliar.

Foucault parece compreender que a arqueologia é uma forma de prática filosófica que se liga à epistemologia histórica, conforme uma tradição da história das ciências na qual Canguilhem figura como caso exemplar. Em 1985, a Revue de Méthaphysique morale homenageou Canguilhem. A contribuição de Foucault apareceu como um artigo que, em 1978, tinha sido originalmente o prefácio da edição americana do livro $O$ normal e o patológico ${ }^{8}$. Mantido em suas linhas gerais, o artigo de Foucault retraça o caso Canguilhem como uma chave de interpretação de várias questões e, inicialmente, tratava do significado político da epistemologia de Canguilhem, segundo o estatuto particular que a disciplina história das ciências obteve com o autor. Foucault faz a seguinte afirmação, no mínimo contundente para a compreensão de seu pensar:

Retirem Canguilhem e vocês não compreenderão grande coisa sobre uma série de discussões que ocorreram entre os marxistas franceses, vocês não apreenderão, tampouco, o que há de específico em sociólogos como Bourdieu, Castel, Passeron e aquilo que os marca tão fortemente no campo da sociologia. Vocês perderão todo um aspecto do trabalho teórico feito pelos psicanalistas e, em especial, pelos lacanianos. E ainda, em todo

\footnotetext{
${ }^{7}$ Voltaremos ao tema quando da discussão sobre a noção de recorrência na arqueologia.

${ }^{8}$ Cf. FOUCAULT, 2001b, p. 429-442.
} 
o debate de ideias que precedeu ou seguiu o movimento de 1968, é fácil encontrar o lugar destes que, de perto ou de longe, foram formados por Canguilhem (FOUCAULT, 2001b, p. 1583).

O pano de fundo sobre o qual a interrogação histórica da arqueologia desenrola-se pode ser assinalado, assim, conforme o mote dado pelo próprio Foucault a respeito da filosofia contemporânea na França. Vale a pena recuperar alguns dados. Segundo Foucault, depois de proferida a conferência As Meditações Cartesianas, a fenomenologia penetrou na França, a partir de 1931, engendrando dois tipos de leituras do trabalho de Husserl: uma interpretação calcada na filosofia do sujeito (Sartre e $A$ transcendência do Ego de 1935) (SARTRE, 1972) e outra linha de interpretação que se remontaria aos "problemas fundadores da filosofia de Husserl" (FOUCAULT, 2001b, p. 430): o formalismo e o intuicionismo, isto é, a interpretação marcada pela teoria da ciência (Cavaillès e suas teses de 1938, Método axiomático e formalismo - Ensaio sobre o problema do fundamento das matemáticas) (CAVAILLÈS, 1938). Animada por essa segunda interpretação, a questão clássica da Aufklärung (uma história da razão e a dimensão histórico-crítica da filosofia) teria sido reativada na França, fazendo-se entrar, sobretudo nos anos 1960, pela história das ciências. Em linhas gerais, esta desenvolverá ao seu modo o problema do papel e do estatuto do saber. Foucault diz:

[...] na França, é sobretudo a história das ciências que serviu de suporte para a questão filosófica sobre o que tinha sido a Aufklärung: as críticas de Saint-Simon, o positivismo de Comte e seus sucessores, de certo modo, foram bem uma maneira de retomar a interrogação de Mendelssohn e de Kant na escala de uma história geral das sociedades (FOUCAULT, 2001b, p. 1585).

Foucault expressa assim que, na prática histórico-epistemológica inaugurada por Canguilhem, reuniram-se os elementos de toda uma clivagem de debate de ideias que puderam fomentar esses "étranges années soixante". Canguilhem surge como um verdadeiro fio de Ariadne por meio do qual Foucault sugere um importante quadro geral do pensamento contemporâneo na França:

Sem desconhecer as clivagens que puderam, durante estes últimos anos e desde o final da guerra, opor marxistas e nãomarxistas, freudianos e não-freudianos, especialistas de uma disciplina e filósofos, universitários e não-universitários, teóricos e políticos, parece-me que poderíamos encontrar uma outra linha de partilha que atravessa todas estas oposições. Tal linha é aquela que separa uma filosofia da experiência, do sentido, do sujeito e uma filosofia do saber, da racionalidade e do conceito. De um lado, uma filiação que é esta de Merleau- 
Ponty e Sartre; de outro, esta de Cavaillès, Bachelard, Koyré e Canguilhem. Sem dúvida, esta clivagem vem de longe e poderíamos seguir seus traços através do século XIX: Bergson e Poincaré, Lachelier e Couturat, Maine de Biran e Comte (FOUCAULT, 2001b, 1583).

A história das ciências, tradição de uma filosofia do saber, da racionalidade e do conceito, reconhece-se, então, de modo privilegiado no pensamento contemporâneo francês, no que será denominado de epistemologia histórica. Mas Canguilhem singularizaria esse momento para o que Foucault toma quatro aspectos da história epistemológica, desde os quais pode assinalar a singularidade da história das ciências de Canguilhem.

O tema propriamente histórico de Canguilhem, como se sabe, foi o das ciências da vida. Ele ampliou a atuação da história das ciências a partir de pontos essenciais da tradição epistemológica. Se a história das ciências foi, inicialmente, a história de algumas ciências tidas como "nobres", devido à sua antiguidade e formalização, ou mesmo à sua dedutibilidade sempre possível (matemática, astronomia, mecânica, física), Foucault ressalta que, com Canguilhem, essa disciplina passou a se preocupar com o campo da biologia e da medicina. Nelas, tudo pareceria alheio "aos hábitos da filosofia". Em outras palavras, Foucault lembra que se trata de um campo negligenciado, devido a uma velha associação histórica entre elas e os "fascínios da imaginação", modo de fazer perceber que a baixa formalização teórica também vinha acompanhada de um fundo discursivo prenhe de construções imagéticas. Nessa ampliação da dignidade filosófica que tais disciplinas adquirem com Canguilhem, parece que a posição epistemológica é, por assim dizer, reinaugurada através do remanejamento de determinados conceitos. Senão, vejamos.

Canguilhem inovou na história das ciências pelo uso que fez do conceito de descontinuidade e pelo método que se refere a ela como consequência, a questão da recorrência. A descontinuidade seria singular em Canguilhem por duas razões: primeiro, porque não seria nem um postulado, nem um resultado da/na história. A descontinuidade é um tipo de atitude epistemológica, uma maneira de fazer. A decorrência que se observa, então, é a de que uma opção pelo descontínuo deve significar uma alteração de ponto de vista, não a construção de uma teoria histórica. Tal alteração é a instauração do ponto de vista do epistemólogo. Mas de que exigência nasceria esse ponto de vista? Por que precisa fazer uma história descontinuísta? Foucault diz que o próprio objeto de que ela trata exige esse modo descontínuo de fazer. O vivente parece ofertar ao epistemólogo da vida esta implicação sempre dada do homem que ocupa um lugar específico na ordem de todos os viventes. Destarte, a segunda razão que singulariza a descontinuidade em Canguilhem é a complexidade de referência ao verdadeiro e ao falso. A história é uma descontinuidade paradoxal, pois convive, sem espantos, com a admissão da verdade das ciências. Aceita, 
pois, que estas, enquanto produtoras de normas internas, deem a si mesmas os objetos verdadeiros; aliás, é sua condição de existência enquanto discurso. Tanto melhor: é em razão desse posicionamento que a investigação pode iniciar a crítica histórica, o que não significa confundir-se com tal normatividade por assim dizer interna das ciências. Certifica-se Foucault:

\begin{abstract}
A história das ciências não é a história do verdadeiro, da sua lenta epifania, ela não poderia pretender contar a descoberta progressiva de uma verdade sempre inscrita nas coisas ou no intelecto, salvo a imaginar que o saber atual a possui, enfim, de uma maneira tão completa e definitiva que ele pode medir o passado a partir dela (FOUCAULT, 2001b, p. 1588).
\end{abstract}

Rejeitada a verdade como norma da história, ou mais exatamente, rejeitada a história das ciências como ascensão progressiva da verdade porque acatar isso seria avaliar as ciências segundo um critério absoluto do saber - a referência à verdade, todavia, não se ausenta. Foucault sabe que fazer a história de descontinuidades pode ser simplesmente fazer descrições de ideias que emergem e se apagam. Assim, ele deve completar com uma adversativa esclarecedora:

E, no entanto, a história das ciências não é uma pura e simples história das ideias e das condições em que elas apareceram antes de se apagarem. Não se pode, na história das ciências, tomarmos a verdade como adquirida, mas não se pode, tampouco, fazer a economia de uma relação ao verdadeiro e de uma relação à oposição verdadeiro e falso. É esta referência à ordem do verdadeiro e do falso que confere a essa história sua especificidade e sua importância (FOUCAULT, 2001b, p. 1588).

A descontinuidade assim entendida só pode ser encampada, efetivamente, como um modo de fazer em Canguilhem. Esse procedimento é exigido pela "natureza" da verdade nas ciências; afinal, que outra forma senão a "forma da descontinuidade" indicaria a operação de retificação, correção, recobrimento de discursos que serão finalizados por um dizer verdadeiro, na expressão tomada diretamente de Canguilhem? Há um mundo epistemológico de verdades descontínuas criado do próprio fazer do historiador e não de descontinuidades generalizadas que operariam de modo homogêneo. Canguilhem, garante Foucault, preveniu-nos desse perigo:

Frequentemente, o pesquisador de rupturas acredita, à maneira de Kant, que um saber científico se inaugura por uma ruptura única, genial. Frequentemente, também, o efeito de ruptura é apresentado como global, afetando a totalidade de uma obra científica (CANGUILHEM, 1977, p. 25). 
O autor nos lembra da dificuldade que há em empreender a possibilidade de uma história das categorias do pensamento científico quando se pensa, de saída, a história da ciência sob "a categoria do progresso das luzes" (CANGUILHEM, 1977, p. 20). Trata-se de um afastamento perseguido intensamente por Canguilhem, pois, como dissemos, é pela busca de campos epistêmicos que praticar uma história para além de um passado da ciência torna-se possível. Este passado é um conceito vulgar para o autor, porquanto impõe um plano contínuo estabelecido sobre o qual o historiador se move segundo o interesse de um presente do objeto, visto como definitivo em seu progresso. A verdade no interior do discurso científico, para falar em outros temos, é para a epistemologia sua norma ou a descrição correta de objetos; trata-se de buscar a coerência interna do discurso sem um valor normativo prédeterminado. ${ }^{9}$

Trata-se de uma importante marca da epistemologia histórica: a ideia de que tolher uma história das ciências, como soberana reprodutora de suas normas internas, exige uma instalação no conteúdo dos enunciados científicos. É nesse sentido que se pode apenas praticar uma história desse tipo, já que ela leva a instalar-se na forma de seus discursos. A referência à ordem do verdadeiro, como diz Foucault, leva necessariamente ao método recorrente. Mas recorrência não é uma maneira de julgar o presente do saber sob a totalidade descrita; por consequência, o sentido da recorrência é haurido dessa instalação nos enunciados científicos: a autossubversão é própria dessa ocupação persistente e minuciosa do discurso, cuja operação mostra-se como "transformações sucessivas deste discurso verídico". Elas produzem, assegura Foucault, "[...] ininterruptamente, remanejamentos em sua própria história; o que, por muito tempo, tinha se permanecido um impasse se torna um dia solução: um experimento lateral se transforma em um problema central em torno do qual todos os outros se põem a gravitar [...]" (FOUCAULT, 2001b, p. 1589).

Em suma, o que Foucault apreende e ressalta como a história das ciências em Canguilhem é a própria afirmação da descontinuidade que, doravante, será uma ordenação latente de discursos verídicos. A referência a essa ordem implica a redefinição da recorrência. Ela passa a ser o móvel de discursos que se recobrem de verdades descontínuas. Compreendendo assim o legado de Canguilhem, Foucault certamente tem em mente a distinção de

\footnotetext{
9 Lemos a seguinte passagem: "Neste texto ( $O$ materialismo racional), a tese da descontinuidade epistemológica do progresso científico é sustentada por argumentos retirados da história das ciências no século XX, da pedagogia das ciências, da necessária transposição de sua linguagem. Bachelard termina com uma variação sobre o duplo verdadeiro-verídico. 'A ciência contemporânea é feita da pesquisa de fatos verídicos e da síntese de leis verídicas'(Apud Bachelard, Le matérialisme rationnel, p. 86). A veracidade ou o dizer-verdadeiro da ciência não consiste na reprodução fiel de alguma verdade inscrita nas coisas ou no intelecto desde sempre. O verdadeiro é o dito do dizer científico" (CANGUILHEM, 1977, p.21).
} 
certos interesses: a diferença entre o interesse histórico do cientista e o interesse do epistemólogo. Aquele é afeito à normatividade interna das ciências e de sua narrativa, sempre cronologicamente orientada pela referência a um passado desdobrado no objeto do presente. Ao contrário, o interesse do epistemólogo é dado por sua vocação à historicidade, e não um complemento de seu saber tácito, como o é para o cientista. Ele é animado pelo problema de obter uma

[...] sucessão manifesta de enunciados, mais ou menos sistemáticos, com pretensão de verdade, o encaminhamento ordenado latente, agora apenas perceptível em que a verdade científica presente é o termo provisório, Mas porque isto é principal e não auxiliar, o interesse do epistemólogo é mais livre que o do cientista (CANGUILHEM, 1977, p. 18).

No interior do percurso foucaultiano, podemos marcar alguns direcionamentos específicos da descontinuidade que será, ao cabo, compreendida como transformação. Ao preço de sermos sucintos demais, enumeremos: (1) Na História da Loucura: uma clara descontinuidade entre práticas e instituições, uma vez que a loucura é analisada segundo suas "concretizações" institucionais e não pelo desenvolvimento teóricoconceitual - descontinuidade, portanto, em favor do domínio institucional em relação a tantos outros tipos de discurso; (2) Em $O$ Nascimento da clínica, há um privilégio do conceito, mas na verdade ele cumpre o mesmo sentido de ruptura da obra anterior, delimitando mais seu trabalho; nessa obra, assim, a teoria médica é sempre justaposta ao espaço social, sendo as rupturas sempre orientadas tanto no campo exclusivamente teórico quanto aquelas que vão sendo exigidas nas instituições médicas surgidas especificamente no século XIX - descontinuidade que atravessa, pois, o campo teórico como o espaço social que lhe dá novos objetos; (3) Em As palavras e as coisas, a ruptura diz respeito à busca, conforme experiências teóricas heterogêneas, dos saberes que se ordenam em epistémê; sendo a mais conhecida, portanto: trata-se da descontinuidade como limiares entre campos epistêmicos que poderiam, inclusive, ser encarados como contínuos entre si, se pensarmos que uma epistémê cede lugar à outra, pelo esgotamento de sua extensão arqueológica.

Ora, A arqueologia do saber congregará e justificará, em retrospectiva, o uso desses sentidos de descontinuidade: é um nome que o arqueólogo dá às transformações discursivas, portanto, um modo de fazer, para cumprir a linha canguilheminiana de seu pensar arqueológico:

A arqueologia desarticula a sincronia dos cortes, como teria desfeito a unidade abstrata da mudança e do acontecimento. A época não é nem sua unidade de base, nem seu objeto: se fala sobre ela, é sempre a propósito de práticas discursivas determinadas e como resultado de suas análises. A época 
clássica [...] é o nome que se pode dar a um emaranhado de continuidades e descontinuidades, de modificações internas às positividades, de formações discursivas que aparecem $e$ desaparecem. Da mesma forma, a ruptura não é, para a arqueologia, o ponto de apoio de suas análises, o limite que ela mostra de longe, sem poder determiná-lo nem lhe dar uma especificidade: a ruptura é o nome dado às transformações que se referem ao regime geral de uma ou várias formações discursivas (FOUCAULT, 2002, p.198).

Retenhamos, enfim, essa opção pela descontinuidade como prática do historiador. Na aurora epistemológica de Canguilhem, pode-se captar o elemento de maior impacto na arqueologia de Foucault: a atitude de historiador é uma retroanálise das verdades das ciências. Por esse termo, Canguilhem compreende a abertura às pretensões de verdade dos discursos da ciência. Tais pretensões se oferecerão a Foucault como o ponto notável a partir do qual o arqueólogo procederá à sua modificação, o que acabará por expressar, não uma tensão e uma diferença fundamental entre epistemologia e arqueologia, mas, ao contrário, um deslocamento que a arqueologia fará em relação ao papel da filosofia - e da verdade -, nessa história das ciências. O germe da novidade arqueológica reside, dessa maneira, na necessidade de aprofundar-se essa perspectiva de investigação, já aventada por Canguilhem, em que não há nem uma oposição fundamental entre descontinuidade epistemológica e arqueológica, nem propriamente uma neutralização da recorrência; há, sim, uma reformulação geral sobre $o$ que se faz na história.

As análises de Delaporte (2011) mostram muito bem que o afastamento de Canguilhem da epistemologia de Bachelard está fundamentalmente ligado ao novo fazer da epistemologia que passa a enxergar "que um dos limites da história epistemológica reside na sua incapacidade de integrar práticas não científicas e não discursivas. Ora, esta impossibilidade, parece-lhe (a Canguilhem), não é senão a contrapartida negativa de uma história que se quer, no essencial, história normativa" (p. 338). Daí que a epistemologia de Canguilhem parece tender a uma epistemocrítica (p. 338).

Parece-nos, portanto, que estabelecer uma descontinuidade, advinda do conceito, é mais um ponto de contato com a tradição da epistemologia histórica do que propriamente um elemento inovador das histórias que Foucault propõe nas suas investigações arqueológicas. E tal conclusão não vale apenas no contexto de seus primeiros trabalhos. Se pudéssemos avançar para análises ulteriores do pensamento de Foucault, levantaríamos algumas análises em favor da ideia de que a descontinuidade permanece uma marca da própria prática genealógica foucaultiana.

Em $O$ poder psiquiátrico, por exemplo, uma importante descontinuidade entre medicina clínica e medicina psiquiátrica é firmada de modo muito claro: enquanto que o diagnóstico diferencial das doenças tinha 
sua base objetiva marcada pela possibilidade de determinar o patológico na forma da lesão localizada no corpo, a medicina psiquiátrica enfrentaria justamente esta ausência de um corpo que lhe aparecesse como domínio objetivo. Se para medicina clínica a doença é plenamente localizável porque o regime de visibilidade da anátomoclínica descobre este exame profundo do corpo morto, a medicina psiquiátrica estará ligada a um diagnóstico absoluto sobre a loucura - é o ou não loucura? - em que o corpo está completamente ausente. Daí a necessidade de interpor a descontinuidade com a medicina clínica: a "posteridade psiquiátrica da crise clássica" terá de enfrentar o problema de produzir para seu saber uma prova não do tipo diferencial, mas uma prova de realidade da loucura (FOUCAULT, 2006, p. 348). Este problema, como se nota ao lermos o curso 1973-1974, postulará uma nova descontinuidade: apenas a neurologia inventará, como uma espécie de correlato objetivo do corpo que psiquiatria não podia dispor, um corpo possível de, nele próprio, correlacionar loucura e sintoma. Foucault desenvolve aí a ideia de corpo neurológico quando o saber médico - agora em vias de ser batizado de neurológico - passa a introduzir a "faradização localizada" (FOUCAULT, 2006, p. 390) para obter, assim, um corpo dentro de um sistema de estímulo-resposta muscular. Ora, percebamos que o mesmo s campo discursivo do saber médico só pode atuar como produtor de diferentes corpos-sujeito na história segundo a descontinuidade que o formula: a medicina anátomoclínica, fundando-se na objetividade de um corpo morto, constitui o problema para a psiquiatria de não possuir este mesmo, digamos, acesso direto ao corpo de loucura. Esta ausência de um corpo psiquiátrico sugere que é a neurologia o campo do saber médico no qual a antiga aspiração do poder psiquiátrico de encontrar um correlato orgânico para a doença mental se realiza ${ }^{10}$.

\section{Recorrência: a dimensão atualizante da arqueologia}

Mas se a descontinuidade surge como esta espécie de começo possível da arqueologia, ela vai par a par com outro efeito vindo da proximidade da epistemologia: a recorrência. Segundo Foucault é preciso diferenciar três tipos de história das ciências que, por sua vez, se referem a como emerge um sistema de formação de enunciados. Um limiar de formalização é quando um discurso de racionalidade científica aparece para definir seus axiomas, seus elementos teóricos, estruturas proposicionais e as mudanças aceitáveis. Este limiar é, portanto, a própria constituição do "edifício formal" de um discurso científico (FOUCAULT, 2002, p. 209). Este tipo de emersão de um sistema de enunciados científicos permite-nos falar em uma história da ciência como uma análise recorrencial. A

\footnotetext{
${ }^{10}$ Basta acompanhar a aula de Foucault (2006, p.387-437) de 6 de fevereiro de 1974 para percebermos que a neurologia seria o novo campo do saber médico que enseja um novo capítulo da funça-psi.
} 
transposição de um limiar de formalização faz com que um discurso científico, por assim dizer, se interiorize em sua constituição formal. De uma ciência constituída, a análise histórica a ser feita é esta que se relaciona de maneira estrita com sua formalização, ou seja, discurso formalizado para quem o "passado se revela como caso particular, modelo ingênuo, esboço parcial e insuficientemente generalizado, de uma teoria mais abstrata, mais poderosa ou de mais alto nível" (FOUCAULT, 2002, p. 212). Foucault apresenta o saber matemático como exemplo deste limiar de formalização e de história recorrencial. Que se acentue: a recorrência é, portanto, a avaliação histórica do que é o passado de uma ciência para esta ciência, enquanto regida formalmente por regras internas.

Ao limiar de cientificidade, segundo Foucault, está relacionado a história epistemológica. Este limiar é a emersão de um discurso científico que, tendo várias figuras epistemológicas em seu funcionamento interno, convive com certas exterioridades que também lhe determinam. Trata-se de um limiar em que o valor científico deve ser pensado desde um estado précientífico, ou melhor, que figuras epistemológicas diversas assumem o mesmo valor de conceitos carregados de metáforas e imaginações; este limiar engendra uma história que deseja saber "como uma ciência se estabeleceu acima e contra um nível pré-científico que, ao mesmo tempo, a preparava e resistia a seu avanço, e como pôde transpor os obstáculos e as limitações que ainda se lhe opunham" (FOUCAULT. 2002, p. 213). Esta história é antirecorrencial porque não se volta para a estrutura formalizada da ciência, nem a analisa como seu dado senão vai ao encontro de tudo que necessitou libertar-se e abandonar para cruzar o limiar de cientificidade (FOUCAULT, 2002, p. 213). Desta maneira, a história epistemológica serve-se da oposição verdade e erro para apurar a racionalidade histórica própria de um discurso cientifico.

O limiar de epistemologização talvez seja o mais difícil de compreensão dos limiares que engendram as três diferentes ideias de história das ciências. Se formalização se liga ao limite como a estruturação interna de uma ciência constituída lançando-se pois, a uma análise estritamente recorrencial de sua história; se a cientificidade é a escansão entre a verdade e o erro de uma ciência constituída em que a limitação se dá, assim, por meio de figuras epistemológicas díspares que clivam o cientifico e não-científico e formulam uma análise do conceito; o que engendraria enquanto história, por seu turno, um discurso científico que deve transpor um limiar de epistemologização? É propriamente o nível arqueológico que este limiar determina: toda vez que o historiador puder assinalar um limiar em que um conjunto de enunciados aspira verificar-se e ser coerente, será possível assinalar que operações discursivas deram lugar a determinadas práticas de saber: 
O terceiro tipo de análise histórica é o que toma como ponto de ataque o limiar de epistemologização - o ponto de clivagem entre as formações discursivas definidas por sua positividade e figuras epistemológicas que não são todas, forçosamente, ciências (e que, de resto, talvez jamais cheguem a sê-lo). Nesse nível, a cientificidade não serve como norma: o que se tenta revelar, na história arqueológica, são as práticas discursivas na medida em que dão lugar a um saber, e em que esse saber assume o status e o papel de ciência. (FOUCAULT, 2002, p. 213)

Nem sempre percebido, o limiar de positividade é que atua na distinção frente às duas outras ideias de história da ciência. Este limiar é o momento em que um único sistema de formação de enunciado acontece como sistema autônomo e individualizado, mas que não é formal, nem avaliado por sua cientificidade, tampouco orientado pelo nível epistemológico. Uma história da ciência do tipo arqueológica parte desse limiar constituído como o ponto equívoco entre uma positividade geral e suas figuras epistemológicas particulares que, eventualmente, se formalizam. Na verdade, a arqueologia situa-se no nível do saber que poderia ser resumido com pergunta por todas as práticas discursivas que deram lugar à determinada formalização, à uma cientificidade específica ou a níveis de epistemologização, sem com isso, confundir-se com estes processos limiares de emergências discursivas. Foucault, assim, pretende diferenciar sua prática histórica não para neutralizar a formalização, a cientificidade e a epistemologização, mas para compreendê-los como finalizações de uma análise, ao mesmo tempo, mais ampla e mais profunda sobre os discursos que adquirem status de ciência e funcionam como tal. Por isso, complementa, definindo a história arqueológica:

\footnotetext{
Empreender nesse nível uma história das ciências não é descrever formações discursivas sem considerar estruturas epistemológicas; é mostrar como a instauração de uma ciência, e eventualmente sua passagem à formalização, pode ter encontrado sua possibilidade e sua incidência em uma formação discursiva e nas modificações de sua positividade. Trata-se, pois, para tal análise, de traçar o perfil da história das ciências a partir de uma descrição das práticas discursivas; de definir como, segundo que regularidade e graças a que modificações ela pôde dar lugar aos processos de epistemologização, atingir as normas da cientificidade e, talvez, chegar ao limiar da formalização (FOUCAULT, 2002, p. 213)
}

Quanto à recorrência, então, seria bastante fácil concluir que ela nada tem a ver com a arqueologia, pertencendo à história dos edifícios formais e, quando muito, funcionaria de modo a amparar a percepção do epistemólogo para quem uma ciência constituída é tanto seu estado atual 
quanto aquilo tudo contra o que resistiu, como fica claro, por exemplo, na ideia de obstáculo epistemológico. Contudo, se formos à letra miúda da epistemologia, a de Canguilhem, estes mundos estão mais próximos do que o comentário especializado por vezes gostaria que estivessem.

A história das ciências de Canguilhem admitia que a historicidade fosse o elemento a manifestar a pretensão de validade do discurso científico, na qualidade de um projeto instruído e a ser empreendido por normas internas. Certamente neste ponto Canguilhem reencontra Bachelard para quem o corte epistemológico ${ }^{11}$ é uma espécie de norma de retificação das ciências, sob o regime de um passado sempre atual. Canguilhem falava-nos, neste sentido, desse tipo de história, feita ao modo da detecção de resultados por um microscópio de laboratório. Ele compreendia, na verdade, que a história das ciências deveria ser tomada ao modelo de uma "escola ou de um tribunal", ou seja, "de uma instituição e de um lugar em que se trazem os julgamentos sobre o passado do saber, sobre o saber do passado" (CANGUILHEM, 1989, p. 13).

Por essa referência, já percebemos que a verdade científica é um espaço de averiguação, no qual "a epistemologia é chamada a fornecer, para a história, o princípio de um julgamento, ensinando-lhe a última linguagem falada por tal ciência" (CANGUILHEM, 1989, p. 13). Para levar a efeito esse princípio, a epistemologia equivaleria não ao simples ato de julgar o passado científico, mas sim àquela ação que, recolhendo no passado para $o$ presente essa linguagem que se tornou estrangeira, consegue expor a constituição de sua cientificidade. Em suma, a epistemologia é a ação crítica da atualidade da ciência, avaliando os objetos que para estas constituem as suas racionalidades de então.

Em que pese sua rejeição à racionalidade científica como referência normativa e, em que pese que a história dos sistemas formais nunca foi um interesse levado a bom termo por Foucault, a arqueologia, nem por isso, deixa de avaliar o passado de um saber. Este tema está desenhado na reflexão sobre a ideia de acúmulo que é um modo de Foucault habilitar o tema da validação dos discursos científicos em sua emergência atual (FOUCAULT, 2002, p. 141). Este tema representa o momento em $A$ arqueologia do saber no qual a recorrência reaparece como problema, ainda que, na nossa compreensão, na forma da hipóstase. ${ }^{12}$ Tudo se passa como se

\footnotetext{
${ }^{11}$ A respeito da noção de corte epistemológico, ver BALIBAR, 1991.

$12 \mathrm{O}$ leitor de A arqueologia do saber deve estar atento ao fato de que Foucault, na formulação desse trabalho, tem no seu horizonte diferentes alvos de ataques nem sempre nomeados, no entanto, perfeitamente reconhecíveis: da história hegeliana aos questionamentos do Círculo de Epistemologia, do sujeito da filosofia Existencialista à ideia de estrutura na Linguística. Esta variedade de alvos certamente levou-o a uma imensa quantidade de formulações metodológicas para definir o nível enunciativo. Algumas delas são quase que só aventadas neste escrito de Foucault. Chamamos atenção, por isso, para este aspecto de hipóstases da reflexão de A arqueologia do saber, sobretudo, nas ideias de acúmulo e materialidade repetível do enunciado.
} 
a análise enunciativa mantivesse uma relação tão específica com o tempo do discurso que Foucault é levado, ao preço de uma abertura vastíssima, a postular o acúmulo como duração, já que os enunciados são passíveis de acumularem-se tão-somente "na espessura do tempo em que subsistem, em que se conservaram, em que são reativados, e utilizados, em que são, também, mas não por uma destinação originária, esquecidos e até mesmo, eventualmente, destruídos" (FOUCAULT, 2002, p.140). A análise enunciativa disporia, assim, de mecanismos específicos de acúmulo como duração: a remanência, a aditividade e a recorrência (FOUCAULT, 2002, p. 140-141). Toda atenção neste ponto da re-caracterização da recorrência. Façamos a extração dessa ideia. Foucault afirma que (1) a recorrência é um tipo de passado como antecedência ativa dos discursos:

A análise enunciativa supõe, finalmente, que se levem em consideração os fenômenos de recorrência. Todo enunciado compreende um campo de elementos antecedentes em relação aos quais se situa, mas que tem o poder de reorganizar e de redistribuir segundo relações novas. Ele constitui seu passado, define, naquilo que o precede, sua própria filiação, redesenha o que o torna possível ou necessário, exclui o que não pode ser compatível com ele (FOUCAULT, 2002, p. 141).

A recorrência também possui (2) um valor normativo pela verdade como aquisição:

\begin{abstract}
Além disso, coloca o passado enunciativo como verdade adquirida, como um acontecimento que se produzia, como uma forma que se pode modificar, como matéria a transformar, ou, ainda, como objeto de que se pode falar( FOUCAULT, 2002, p. 141)
\end{abstract}

Ela ainda acampa a memória, o esquecimento, a pesquisa pelo sentido ou a repressão do sentido como modos singulares da própria recorrência. Ou seja, (3) as formas tradicionais de vincular o passado de uma ciência ao seu presente não é internamente determinada pela formalização da ciência, tampouco produzida só um por uma referência normativa à determinada cientificidade. A recorrência foucaultiana, diferentemente, parte dessas figuras como o mote para avaliar a densidade do acumulo que não é retorno mas preservação presente que modifica e por vezes desaparecer como enunciação:

Em relação a todas essas possibilidades de recorrência, a memória e o esquecimento, a redescoberta do sentido ou sua repressão, longe de serem leis fundamentais, não passam de figuras singulares (FOUCAULT, 2002, p. 141) 
Em uma palavra, a epistemologia de Canguilhem e a arqueologia de Foucault determinam de modo muito próximos o valor normativo de uma ciência ou de um saber: ele próprio deve ser avaliado no presente de uma ciência ou de um discurso. Em que sentido a arqueologia seria então antirrecorrencial? É que ambas, de fato, não admitem formular um presente como juiz do passado, se por este juízo se compreendermos a avaliação absoluta sobre um passado absoluto. Ora, mas isso não a exime de um determinado tipo de tarefa avaliadora, à qual a epistemologia histórica sempre foi solidária. A epistemologia, tal como a arqueologia, realiza uma crítica da ideia de racionalidade, compartilhando ambas a necessidade de realizar uma prática judicativa das ciências. ${ }^{13}$

A dimensão atualizante se expressa, portanto, segundo este vínculo entre normatividade do discurso e anelo de cientificidade, isto é, na prerrogativa que arqueologia e epistemologia se dão de uma denúncia crítica do presente discursivo: crítica dos saberes que são batizados retrospectivamente pela história tradicional e pela própria narrativa dos discursos internos das ciências, considerado como um objeto dotado de cientificidade inquestionável, um objeto natural. Pesquisar a pretensão de validade é o que gera a ruptura, no âmago de uma nova história que se diz propriamente conceitual. Essa prática histórica é comum a Foucault e aos modelos dos epistemólogos. Uma crítica, cujo vezo é o de retirar a cientificidade como norma externa de avaliação para qualquer história, não se pode pretender, ela própria, científica, senão oferecendo um novo sentido de positividade. Se algum dia a epistemologia se arrogou esse direito, ela o fez na condição de revelar o próprio conceito de cientificidade como mais um termo de que se deve, igualmente, fazer a história.

Outra vez é salutar indicar que a crítica arqueológica não desaparecerá como crítica de um saber local e atual nos trabalhos da genealogia: o saber médico, como crítica de certo dado atual do sujeito medicalizado, não pode dispensar como sua âncora avaliadora, por exemplo, um dado do presente da medicina psiquiátrica. A ideia de que a doença mental é uma função-sujeito expõe este modo de colocar um ponto crítico atual da medicalização. A condição para realizar uma arqueologia da

\footnotetext{
${ }^{13}$ Se insistirmos nessa perspectiva, mesmo Bachelard, para Foucault, já lidava com um estatuto de racionalidade que se orientava pelo que chamou de seus efeitos "menores" como quem se vê aparentado aí por esta atenção aos desvios discursivos da epistemologia bachalerdiana: "Bachelard não hesita opor Descartes a um filósofo menor ou a um sábio... um sábio, creio eu, um pouco... um pouco imperfeito ou fantasista do século XVIII [...]. Fazendo isso, não se trata absolutamente de reconstituir a grande cultura global que é aquela do Ocidente, ou da Europa, ou da França. Não se trata de mostrar que é sempre o mesmo grande espírito que vive, que por tudo formiga, que reencontra o mesmo; eu tenho a impressão, ao contrário, que Bachelard tenta atocaiar sua própria cultura com seus interstícios, seus desvios, seus fenômenos menores, seus pequenos desafinos, suas falsas notas (FOUCAULT, 2001a, 1250).
} 
alienação está lançada na atualidade de um sujeito na história. Um sistema crítico de pensamento não pode fingir a inexistência da modificação atual desse discurso, desde a qual, enfim, o historiador arqueólogo firma seus pés.

\section{0 saber não é o canteiro da epistemologia}

É bem possível que a esta altura o leitor se indague sobre, afinal, qual seria o real distanciamento da arqueologia de Foucault em relação à epistemologia, se conceitos fundamentais dessas práticas, como a descontinuidade e recorrência, acabam pertencendo a uma urdidura de idas e vindas que as fazem se parecer. Esta trama da descontinuidade e da recorrência estão baralhadas propositadamente em nossa análise. Seria incoerente afirmar um distanciamento "real" entre arqueologia e epistemologia histórica. Mas igualmente, seria inconsistente deixá-las indiferenciadas.

A conhecida expressão "o saber não é o canteiro epistemológico que desapareceria na ciência que o realiza" mostra a clareza com que Foucault pensa a distância entre seu fazer arqueológico e os mestres que o precederam. "A ciência (ou que passa por tal)", indica ele, "localiza-se em um campo de saber e nele tem um papel que varia conforme as diferentes formações discursivas e que se modifica de acordo com suas mutações" (FOUCAULT, 2002, p. 206). O saber não é o canteiro epistemológico das ciências porque a arqueologia percebe que tal canteiro está em relação permanente com uma formação discursiva. Ou, para dizer explicitamente a estratégia de leitura de Foucault, a própria epistemologia aqui é lida arqueologicamente como se o pensador voltasse para ela um olhar de profundidade. O limiar de cientificidade, como vimos, é esta região limítrofe para o epistemólogo desde a qual ele poder historiar o conceito que se apresentará sob uma diversidade de figuras epistemológicas. Tematizar as ciências em sua historicidade é situar-se "em uma perspectiva filosófica" e distinguir-se "das disciplinas propriamente históricas ou científicas" (MACHADO, 1981, p. 10-11). A epistemologia apareceria, assim, como a filosofia que tematiza a racionalidade através da ciência.

A partir da filosofia de epistemólogo é que a análise arqueológica procede a uma ampliação: o limiar de epistemologização é uma vizinhança equívoca entre as formações discursivas e todas as figuras possíveis dos saberes a elas referidas. Praticar a arqueologia é estudar as condições de existência de um discurso e suas várias pretensões epistemológicas que não são apenas científicas. A história arqueológica não se pauta pela ciência como norma de racionalidade, o que não faz dela algo consistente com um limiar de cientificidade. Se a cientificidade não lhe serve como norma, é porque as formações discursivas revelam as regras que instauram domínios de racionalidade mais amplos. 
O saber não é o canteiro da epistemologia porque a possibilidade de uma história dos discursos, recusando o limiar de cientificidade como ponto de partida exclusivo, acaba ampliando, portanto, a ideia cientificidade para uma ideia de discurso como pretensão à verdade. Será possível, doravante, uma arqueologia de toda formação discursiva, leia-se, de toda pretensão de racionalidade: "o essencial” confirma Delaporte (2011):

Reside no fato de que a história epistemológica, como a história arqueológica, impõe a allure de narrativas históricas sem, no entanto, fechar os historiadores em uma forma estereotipada. Há histórias diferentes porque há maneiras distintas de jogar (faire jouer) com a recorrência" (p. 340).

Nisto encontramos a definição, por assim dizer, "acabada" de arqueologia tão bem colocada pelo próprio mestre de Foucault. Sob uma espécie de interpretação de contra fluxo entre mestre e aluno, Canguilhem diz:

Apesar do que diz a maior parte dos críticos de Foucault, o termo arqueologia diz vem o que ele quer dizer. É a condição de uma outra história, na qual o conceito de acontecimento conservou, mas onde os acontecimentos afetam conceitos e não homens. Uma tal história deve, também ela, reconhecer cortes, como toda história, mas cortes situados diferentemente (CANGUILHEM, 1967, p. 607).

Por isso, pelo que fica exposto até aqui, não pretendemos certamente invalidar o importante filão que entrecruza arqueologia e epistemologia histórica nas suas claras diferenças, mas levar à percepção de que os efeitos dessa paisagem podem, se se quiser fazer da arqueologia um método novo, repreender em demasia o funcionamento da arqueologia como fruto da descontinuidade histórica e da antirrecorrência. Podemos pensar que mesmo as preocupações ulteriores de Foucault sobre o sujeito, o poder e a ética estarão visivelmente marcadas por esta rotina da norma conceitual: o recurso a uma crítica discursiva localizada em um conceito jamais se ausentará em Foucault como indicamos.

Em suma, se por um lado, a arqueologia em face da história epistemológica é neutralizadora da questão da cientificidade, por outro, deve-se entender essa "neutralização" não como se a epistemologia portasse uma ideia de cientificidade que se aparenta à verdade do objeto das ciências. Por esta via, a história epistemológica, ao menos esta praticada por Canguilhem, correria o risco de se ver comprometida com o elemento que justamente problematiza: a condição normativa de toda ciência que se oferece como matéria de estudo à prática epistemológica. A ruptura que resulta em descontinuidades e, portanto, em uma afirmação de verdades descontínuas nas ciências, advém de uma tarefa judicativa. Todavia, essa 
tarefa não se impõe como avaliadora de um passado extensivo da ciência, mas de uma regionalidade intensa, tarefe própria ao historiador dos campos epistemológicos ou epistêmicos. ${ }^{14}$

\section{Conclusão}

A proximidade da arqueologia de Foucault com a epistemologia de Canguilhem poderia ser subsumida à ideia de que, ambas, procedem a uma descrição das pretensões de verdade: uma na ciência, a outra, nos saberes. Poderíamos desenvolver este tema de modo a estudar o tema da verdade nos dois autores. Contudo, à guisa de nossa conclusão, diríamos que redefinir a relação entre cientificidade, filosofia e verdade é precisamente o tema em circulação e debate nesta tradição da epistemologia histórica francesa.

Há uma reunião de entrevistas de 1965 que trouxe à mesa Badiou, Canguilhem Dreyfus, Hyppolite, Ricoeur e Foucault. Nela podemos mesurar a importância da relação entre cientificidade, filosofia e verdade. A questão debatida na mesa foi a possível contradição entre duas afirmações: a de Canguilhem: "Não há verdade senão científica" (Ou: "Não há verdade filosófica"), justaposta à de Hyppolite "Não há erro em filosofia". Canguilhem esclarece, de pronto, que, quando afirma a não-existência de uma verdade filosófica, não exprime com isso nem uma indiferença do filósofo à verdade, nem uma ausência de interesse da filosofia pela essência da verdade. Trata-se, ao revés, de compreender que a relação mantida pela filosofia com as verdades definidas pelas ciências "é um objeto de meditação" (FOUCAULT, 2001a, p.476), e cumpre, aqui, observar o termo exato usado por Canguilhem: trata-se de uma meditação que se realiza não sobre $a$ verdade, mas sobre "as verdades definidas progressivamente pelas ciências" (FOUCAULT, 2001a, p.477).

Em algumas frases, o epistemólogo define com precisão sua atividade: instalar-se no interior das verdades científicas que, no seu avanço próprio - em sua normatividade-, permite que o novo historiador realize não uma pesquisa especializada que seria reincidir em um objeto-verdade das ciências, mas sim uma meditação. Impõe-se, desse modo, a definição da tarefa da filosofia, já que Canguilhem afirma algumas vezes que as ciências

\footnotetext{
${ }^{14}$ Podemos dizer, para prestar algum esclarecimento final, que há uma distinção de foco entre a coupure epistemológica e a epistêmica. Enquanto a epistemologia pratica uma análise da regionalidade intensa a partir das fraturas conceituais nas ciências, a arqueologia pratica uma análise da regionalidade extensa a partir dos cortes enunciativos. Lá saímos de objeto a objeto e, de algum modo, um projeto normativo interno às ciências precisa se justificar em face das rupturas epistemológicas; na arqueologia, diferentemente, deslocamonos para o campo dos enunciados que, uma vez justapostos, encontram sua coerência no trabalho extensivo ao recorrer a toda sorte de conceitos, incoerências, contradições, metáfora, imagens etc.
} 
não podem tratar seus objetos segundo o grau de universalidade com que eles podem ser encarados pela filosofia. Esta é a tarefa da filosofia:

[...] a filosofia deve confrontar certas linguagens especiais, certos códigos com o que permanece profunda $\mathrm{e}$ fundamentalmente ingênuos na experiência vivida. A filosofia não se endereça a ninguém em particular, mas universalmente a todos. E a relação entre o pensamento filosófico e o pensamento das diferentes disciplinas científicas é uma relação concreta e nunca abstrata ou especial (FOUCAULT, 2001a, p.478).

Sem um enraizamento em terreno próprio, a filosofia não deixa, contudo, de referir-se a uma ordem de verdade. Reiteradas vezes, Canguilhem adverte que o "valor próprio de verdade" não convém à filosofia, embora ela tenha seu valor. A filosofia é restauradora de uma totalidade cósmica que acabara por se perder, necessariamente, na diversidade das ciências. A necessidade intelectual da filosofia aparece no mesmo passo com o qual as ciências dirigem-se a um modo de explicação cada vez mais rigoroso, técnico, verdadeiro: para a ciência "[...] o que é [afirma Canguilhem] é o que ela define progressivamente como sendo o verdadeiro" (FOUCAULT, 2001a. p.481). A filosofia é sua confrontação, a dos valores verdadeiro e falso, no mundo onde nós estamos. Por essa razão, o discurso filosófico a respeito do que as ciências entendem por "verdade" não pode ser definido, ele mesmo, como um discurso verdadeiro. Inesperada fenomenologia de Canguilhem.

A intervenção de Foucault aparece quase imperceptível, porém ela incide justamente sobre o espaço da produção dessa verdade, digamos, ali debatida: não é possível uma verdade da verdade, visto que Canguilhem e Hyppolite concordam que há um espaço natural da verdade que são as ciências. A propósito desse raciocínio, Hyppolite dá um exemplo: "Embora, para Kant, por exemplo, a analítica transcendental representasse um tipo de verdade, isto não é mais verdade para nós hoje. Estamos em uma antropologia que se ultrapassa, não estamos jamais em um transcendental" (FOUCAULT, 2001a, p.480). Não fosse por essa rápida intervenção, não se poderia captar a diferença foucaultiana a respeito da produção da verdade nas ciências: "Sim [replica Foucault], mas mesmo a antropologia sobre a qual infelizmente nós refletimos muito frequentemente, é precisamente um transcendental que se desejaria verdadeiro ao nível natural". E aduz em defesa de sua posição: "[...] a partir do momento em que tentamos definir uma essência do homem que poderia se enunciar a partir dele mesmo e que seria, ao mesmo tempo, o fundamento de todo conhecimento possível e de todo limite possível do conhecimento, estamos em pleno paralogismo" (FOUCAULT, 2001a, p.480).

O modo pelo qual Foucault situa sua mutação, no tocante à produção da verdade nas ciências, torna-se tanto mais compreensível quando se 
destaca sobre o fundo da antropologia kantiana. Parece que ela é tomada aqui como um contraexemplo, usado para desnudar a espécie de espaço natural que impede, justamente, que tomemos um discurso filosófico por verdadeiro ou falso. Foucault não pretende, com a expressão "estarmos em pleno paralogismo", validar o transcendental como um tipo de verdade que se efetiva no nível natural, numa tentativa de aferir a verdade filosófica pela antropologia. Ao contrário, Foucault revela o motivo pelo qual podemos expressar a inexistência de categorias objetivas preexistentes à ciência: elas são categorias da verdade, porque essencialmente compreendidas sob as condições que as tornaram possíveis, ou seja, com o fundamento antropológico do sujeito transcendental. Por isso que Foucault concorda em não admitir a verdade ou a falsidade de um discurso filosófico, mas impõe que se pergunte por esse espaço naturalizado da verdade, ou melhor, que se pergunte ao discurso, qualquer que ele seja, por sua vontade de verdade. Eis aí a mutação em que a arqueologia se fia. Entre os debatedores, esta mutação acaba por ser exposta na fala final feita por Badiou:

Eu diria que, como tudo em filosofia, o desacordo surge, apesar de tudo, no interior de uma definição e de uma questão que permite que nós nos compreendamos uns aos outros; eu quero dizer por aqui, e talvez seja a ironia de sua posição, Canguilhem, que a pretensão de verdade do discurso de seu interlocutor é por você reconhecida, mesmo se o conteúdo de seu próprio discurso consiste em afirmar que o valor da verdade não está aqui em curso (FOUCAULT, 2001a, p.492).

Trocando em miúdos, o valor da verdade para a arqueologia de Foucault é uma prática do valor verdadeiro. É possível ouvir, portanto, ao fundo dessas proximidades interpretativas, entre arqueologia e epistemologia que analisamos, um esforço original de Foucault em redefinir a relação da Filosofia com a verdade. E esta redefinição recorre à história como sua legitimadora. Talvez seja óbvio constatar que, em se tratando de uma nova prática inicialmente dada no campo de certa história das ciências na França "pós-Bachelard", a arqueologia carregue então as marcas de um pensamento epistemológico, o de Canguilhem. Mas a relevância desta proximidade analisada não se restringe ao pertencimento compulsório a um ponto de partida inescapável e não se pode fixar uma filiação inicial como o determinante definitivo de um pensar.

De fato, talvez tenhamos aqui uma problematização histórica mais ampla na qual se inscreve o pensamento foucaultiano e, ao que tudo indica, diz respeito à referência à verdade que fazem estes diferentes pensamentos históricos. É bem possível que ouçamos neste ponto a pergunta ainda a ser reposta, agora do ponto de vista arqueológico: epistemologia histórica ou história epistemológica? Delaporte coloca a questão e nos incita a ver que temos na expressão mais que um problema lexicográfico: estamos com "a questão fundamental da norma em história" (DELAPORTE, 2011, p. 339) 
que pode ser tanto de caráter continuísta quanto descontinuísta. A expressão epistemologia histórica possui ainda a desvantagem de carregar a "atualidade da ciência por norma", isto é, estaria o historiador já fechado em pós e contras prévios fornecidos pela atualidade. A epistemologia é sempre histórica para Canguilhem porque trata-se de ampliar o campo de atuação de uma história que problematiza o ponto atual da racionalidade científica para se interrogar "sobre as relações ente o que é científico e o que não é" (DELAPORTE, 2011, p. 340).

A contribuição indubitavelmente mais significativa da arqueologia de Foucault para a Filosofia é o fato de ela subtrair o pensamento filosófico, de modo radical, de qualquer independência de uma historicidade crítica. Tal qual Nietzsche nos anos 1870 procurou certificar-se de que o erro hereditário dos filósofos foi o fato deles filosofarem sem história, o arqueólogo do saber deseja dar à Filosofia uma relação com a verdade pela história. Por isso, em relação a Canguilhem - e nisto então está a renovação foucaultiana da tradição em questão - Foucault se situaria num campo que não é o da historiografia cientifica contemporânea. Seu campo seria o da epistemografia (épistémografie) ${ }^{15}$ que se propõe inquirir o funcionamento dos discursos como discursos científicos, o que faria tanto da história epistemológica quanto da história arqueológica "ramos" dessa disciplina (DELAPORTE, 2011, p. 340).

Por isso, a Filosofia, segundo o pensamento arqueológico, poderia ser definida como uma escuta insistente do arquivo. Ao ser indagado se o pensador cede à "paixão própria de historiador" cujo desejo é o de responder "ao rumor infinito dos arquivos" (FOUCAULT, 2001a, p. 623), Foucault responde, dizendo:

Um pesadelo me persegue desde a infância: tendo, diante dos olhos, um texto que não posso ler, ou do qual apenas consigo decifrar uma ínfima parte, eu finjo que o leio, sei que o invento: de repente, o texto se embaralha completamente e nada mais posso ler, tampouco inventar, minha garganta se fecha e eu acordo" (FOUCAULT, 2001a, p. 623).

A verdade do discurso é esta insistência de ler a profundidade do discurso nas formas as mais superficiais possíveis: talvez não possamos ler todo o texto, talvez sejamos compelidos a reinventá-lo, talvez o texto se esvaia diante do historiador. A relação arqueológica da Filosofia com a verdade é, pois, este assombro provocado pelo rumor sem fim dos arquivos,

\footnotetext{
${ }^{15}$ Seguindo Delaporte, podemos dizer que vocábulo comportaria dois sentidos que ao cabo ampliam fortemente a ideia da história arqueológica: revela a ideia de um funcionamento como identificado, por um lado, ao funcionamento do discurso científico autêntico - na qualidade de um discurso científico e, por outro lado, pergunta-se por todas as figuras epistemológicas, formações discursivas ou saberes em que o como é "empregado à título de advérbio conjuntivo de maneira (2011, p. 340)
} 
burburinho de funcionamentos concretos de toda linguagem que se quer racional, ou melhor, de todos os discursos que "foram ditos" (Ibidem, p. 623). Daí que embaralhar tradições para ouvir o rumor infinito dos arquivos pode ser a própria estratégia para ler os descaminhos do pensamento de Foucault. 


\section{Referências bibliográficas}

BALIBAR, E. Le concept de "coupure épistémologique" de Gaston Bachelard à Louis Althusser. Écrits pour Althusser, Paris: La Découverte, 1991.

CANGUILHEM, G. "Mort de l'homme ou épuisement du cogito?" Critique. Paris : Éditions de Minuit, T. XXIV, n. 242.

1989. Études d'histoire er philsophie des sciences, 5. ed. Paris: J.Vrin, . Ideologie et rationalité dans l'histoire dês sciences de la vie. Paris: J. Vrin, 1977.

CAVAILLÈS, J. Méthode Axiomatique et Formalisme: Essai sur le probl eme du fondement des mathématiques, Paris: Hermann et Cie, 1938.

DELAPORTE, F. Foucault, 1'histoire et l'épistémoligie. Cahier Foucault, CAhier de L’Herne. Artières, Ph., Bert, J.-F., Gros, F., \& Revel, J. (Editores) Paris, L'Herne, 2011

DESCAMPS, C. As idéias filosóficas contemporâneas na França (19601985). Trad. Arnaldo Marques. Rio de Janeiro: Jorge Zahar, 1991.

FOUCAULT, M. As palavras e as coisas. Tradução de Salma Tannus Muchail. 8a. ed. São Paulo: Martins Fontes, 1999.

. Dits et écrits I - 1954-1975. Paris: Gallimard, 2001a.

. Dits et écrits II - 1976-1988. Paris: Gallimard, 2001b.

Os anormais: curso dado no Collège de France (1974-1975). Trad.

Eduardo Brandão. São Paulo: Martins Fontes, 2001c.

2004

Vigiar e punir. Trad. Raquel Ramalhete. 29. ed. Petrópolis: Vozes,

. História da loucura na Idade Clássica. Trad. José Teixeira Coelho Neto. 8. ed. São Paulo: Perspectiva, 2005.

O poder psiquiátrico: curso dado no Collége de France (1973-

1974). Trad. Eduardo Brandão. São Paulo: Martins Fontes, 2006.

. A arqueologia do saber. Trad. Luiz Felipe Baeta Neves. 6. ed. Rio

de Janeiro: Forense Universitária, 2002.

A sociedade punitiva: curso no Collège de France (1972 -1973).

Tradução Ivone C. Benedetti. - São Paulo: Editora WMF Martins Fontes, 2015.

GROS, F. Michel Foucault. Coll. Que sais-je ?, P.U.F., 2012.

KOYRÉ, A. Études d'histoire de la pensée scientifique. Paris: Presses Universitaire, 1966.

MACHADO, R. Ciência e Saber - A trajetória da arqueologia de Foucault. Rio de Janeiro: Graal, 1981.

RIBAS, T. F. "Foucault, a existência do discurso e a política". In: Marcelo Carvalho; Dirce Eleonora Nigro Solis; Alexandre de Oliveira Torres Carrasco. (Org.). Filosofia francesa Contemporânea. 1ed.São Paulo: ANPOF, 2015, v. 1, p. 513-523. 
. Saber, verdade e política no pensamento de Michel Foucault. Tese (Doutorado) - Universidade Federal do Paraná, Curitiba, 2016. SARTRE, J.P. La transcendance de l'ego. Paris: Vrin, 1972.

$\overline{\text { Autor(a) para correspondência: Carlos Eduardo Ribeiro, Universidade Federal do ABC, }}$ Av. dos Estados, 5001, CEP 09210-580, Santo André - SP. Brasil. c.ribeiro@ ufabc.edu.br 